\title{
Effect of Vitamin D Supplementation on Blood Glucose Homeostasis, BMI and Lipid Profile in Diabetic Patients with Vitamin D Deficiency
}

\author{
Ayah Almaghrbi ${ }^{1}$, Marwa Altarrani ${ }^{1}$, Nagwa Elmighrabi $^{2}$, Hana M Bakoush $^{1} \&$ Ali Ateia Elmabsout ${ }^{1 *}$ \\ ${ }^{I}$ Department of Nutrition, Faculty of Public Health, University of Benghazi, Benghazi, Libya. ${ }^{2}$ School of Health and Society, \\ University of Wollongong, Wollongong, Australia. E mail: ali.elmabsout@uob.edu.ly ${ }^{{ }^{*}}$
}

DOI: http://doi.org/10.38177/AJBSR.2021.3303

Copyright: () 2021 Ayah Almaghrbi et al. This is an open access article distributed under the terms of the Creative Commons Attribution License, which permits unrestricted use, distribution, and reproduction in any medium, provided the original author and source are credited.

\section{ABSTRACT}

Background: Vitamin D deficiency seems to be frequent and involved in pathogenesis of numerous diseases, including metabolic abnormalities and glucose homeostasis. The aim of study was to investigate the effect of vitamin D supplementation on FBS, glycemic control, lipid profile and BMI in diabetic patients with vitamin D deficiency. Methods: A case control study conducted on diabetic and non-diabetic patients include 50 health and 150 diabetic patients. Diabetic patients have no or vitamin D deficiency and health control as well. Both were thereafter FBS, HbAlc measured first time on supplemented vitamin D either 50, 000 UI orally or 200,000 IU IM. After three months all blood parameters were measured include FBS, HbA1C, lipid profile and BMI. T test was used for determination of statistical significant between groups. Results: Vitamin D supplementation had profound effect and control FBS, HbAIC, lipid profile and BMI P< 0.05 on both Types 1 and types 2 diabetes mellitus. However, such effect has no been found in counterpart healthy control with vitamin $D$ deficiency. The regular weekly dose of 50,000 IU were found more promising values on $F B S, H b A 1 C$, lipid profile and BMI P<0.05 than the monthly does. Physical activities of cases and control did not shown to have any cofound factors on FBS, HbAIC, lipid profile and BMI. Conclusion: Vitamin D can be considered as a therapeutic agent along with the other treatments for both types of Diabetes mellitus in which could be deemed to use for routine treatment due to vitamin D deficiency is worldwide problem.

Keywords: Glucose, BMI, Vitamin D, Diabetes mellitus, Supplementation, Lipid profile.

\section{Introduction}

Vitamin D deficiency seems to be frequent and linked to pathogenesis of numerous diseases, including metabolic abnormalities (1). The connotation between vitamin D deficiency and insulin resistance has been suggested (2). A numbers of clinical studies showed that vitamin D supplementation reduces risk of some metabolic parameters such as BMI, total cholesterol (TC), low-density lipoprotein (LDL), triglyceride (TG), glycated hemoglobin (HbA1c), as well as decreases insulin resistance in T2DMpatients (3-5). However, the action vitamin D for reducing risk of metabolic disorders development proposed through vitamin D receptor (VDR) and vitamin D-metabolizing enzymes were detected in various cell types, including pancreatic beta cells and insulin-responsive cells such as adipocytes $(6,7)$. Some evidences suggest that vitamin $\mathrm{D}$ control the numerous sequential events that are responsible for enabling the pancreatic beta cells to secrete insulin, and thereby to control of blood glucose level (8-10). Low vitamin D may diminish calcium's ability to affect insulin secretion. $(11,12)$. In addition, the evidence indicates that vitamin D treatment improves glucose tolerance and insulin resistance (13). However vitamin D deficiency leads to reduced insulin secretion (14). This article investigates the effect of vitamin D supplementation on FBS, glycemic control, lipid profile and BMI in diabetic patients with vitamin D deficiency (15-20).

\section{Material and Methods}

\section{Study Population}

A case control study carried out from beginning of January to the Beginning of April on diabetes and non-diabetes subjects. Diabetes subjects include T1DM and T2DM from diabetes center. Non-diabetes volunteer matching to 
Asian Journal of Basic Science \& Research

Volume 3, Issue 3, Pages 25-35, July-September 2021

diabetes patients were selected from general population and/ or for diabetes center. The total samples size (case and control) were 200 subjects ( 81 male and 119 female) diabetes and non-diabetes with ages ranging between 18-70 years old.

\section{The case and control were categorized as following}

The patients in this study were diabetes and non-diabetes and the sample was categorized as following:

- 100 patients with DM and have vitamin D deficiency.

- 50 patients with DM and have no vitamin D deficiency.

- 25 Healthy with vitamin D deficiency (Control 1) and on vitamin D supplementation.

- 25 Healthy no vitamin D deficiency (Control 2).

\section{Protocol for the study include}

- Measurement of FBS and HbA1C before vitamin D supplementation started and after.

- For lipid profile and BMI measured only once after taken vitamin D for at least 3 months.

All the subjects were followed by doctor in diabetic center in which doctor prescribed vitamin D to the patients.

- On vitamin D weekly dose of 50, 000 IU oral supplementation or injectable monthly dose ranging from 200, 000

IU to 600,00 . The dose common reported in this study was 200,000 IU.

- BMI was measured through weighing weight with minimum clothing and height with bare foot by using SECA balance machine finally BMI was calculated by using weight/Ht $(\mathrm{M})^{2}$.

\section{Questionnaire}

The questionnaire for this study based on 20 items divided into four sections. It contained questions about personal information, demographic and socioeconomic characteristics, biochemical investigations, and anthropometric data.

\section{Ethical statement}

This study was granted approval by the local Ethics Committee of the Benghazi province. Informed written consent was obtained through a consent form that was given to the participants along with the questionnaire.

\section{Statistical analysis}

The data from the questionnaires was entered using Excel. Data set was exported to SPSS v.22 and Epi-info for complete analysis. Statistical analysis was carried out for the complete samples which were created according to measurements in which frequencies and percentages were used. To determine the differences regarding each categorical variable in the groups, $\mathrm{T}$ test was performed to compare the mean of FBS, HbA1C and lipid profile within and between groups. $P \leq 0.05$ was considered to be statistically significant.

\section{Result}

The data collected on 200 subjects were shown that the average ages of subjects were $40 \pm 6$ years old in which about $50 \%$ of patients fall in the age groups between 31-45 years old, followed by those with age groups between 
46-60 years old (30.5\%), whereas the age groups 18-30 and more than 60 years old present by $12.5 \%$ and $7.5 \%$ respectively (Table 1). Regarding gender distribution, it has been found that, approximately $60 \%$ of the subjects female and the rest (40\%) male (Table 1).

Table 1. Age and gender distribution

\begin{tabular}{|ll|r|r|}
\hline & & \multicolumn{1}{|c|}{$\mathrm{N}$} & \multicolumn{1}{c|}{$\mathrm{N} \%$} \\
\hline Patient Age & $18 \_30$ & 25 & $12.5 \%$ \\
& $31 \_45$ & 99 & $49.5 \%$ \\
& $46 \_60$ & 61 & $30.5 \%$ \\
& $>60$ & 15 & $7.5 \%$ \\
& Total & 200 & $100.0 \%$ \\
Gender & male & 81 & $40.5 \%$ \\
& female & 119 & $59.5 \%$ \\
& Total & 200 & $100.0 \%$ \\
\hline
\end{tabular}

In the next family history of Diabetes mellitus has been investigated, and found that approximately $64.5 \%$ did not have family history of DM, mother and father side present by $18.5 \%$ and $10.5 \%$ respectively and those who has parent with DM being least (4.5\%) (Table 2).

Table 2. Family history of diabetes mellitus

\begin{tabular}{|l|r|r|}
\hline & \multicolumn{1}{|c|}{$\mathrm{N}$} & $\mathrm{N} \%$ \\
\hline Mother Yes & 37 & $18.5 \%$ \\
Father Yes & 21 & $10.5 \%$ \\
both mother and father & 9 & $4.5 \%$ \\
& & \\
No & 133 & $64.5 \%$ \\
Total & 200 & $100.0 \%$ \\
\hline
\end{tabular}

In table 3, $50(25 \%)$ were healthy control, and about 52 (26\%) of patients were on insulin therapy while $88(44 \%)$ of patients were on oral hypoglycemic agents. There were about $28 \%$ of patients reported as TIDM and 47\% T2DM (Table 3).

Table 3. Types of hypoglycemic agents and diabetes

\begin{tabular}{|ll|r|r|}
\hline & & $\mathrm{N}$ & $\mathrm{N} \%$ \\
\hline Types of hypoglycemic & Healthy & 50 & $25.0 \%$ \\
agents & control & 56 & $28.0 \%$ \\
& DM insulin & 58 & $44.0 \%$ \\
& DM Tablet & 6 & $3.0 \%$ \\
& DM both & 200 & $100.0 \%$ \\
& Total & 50 & $25.0 \%$ \\
Types of diabetes & Healthy & 56 & $28.0 \%$ \\
& control & 94 & $47.0 \%$ \\
& T1DM & 200 & $100.0 \%$ \\
\hline
\end{tabular}


Glycemic control, fasting blood glucose lipid profile and body weight status have been investigated among case and control as shown in table (4). The mean blood glucose was higher in both DM patients with and without vitamin D deficiency $180 \mathrm{Vs} 171 \mathrm{mg} / \mathrm{dl}$. After diabetic patients received vitamin D, blood glucose has dropped from $180 \mathrm{mg} / \mathrm{dl}$ to $151 \mathrm{mg} / \mathrm{dl}$. Furthermore, $\mathrm{HbA1C}$ also lowered from $8.8 \%$ to $7.5 \%$ while improved lipid profile and BMI (Table 4).

Table 4. Fasting blood glucose, glycemic control and lipid profile among control and cases

\begin{tabular}{|l|c|c|c|c|}
\hline \multirow{2}{*}{} & \multicolumn{3}{|c|}{ Case and control groups } \\
\cline { 2 - 5 } & $\begin{array}{c}\text { DM patients } \\
\text { have vitamin } \\
\text { D deficiency }\end{array}$ & $\begin{array}{c}\text { DM patients } \\
\text { have no } \\
\text { vitamin D } \\
\text { deficiency }\end{array}$ & $\begin{array}{c}\text { Health have } \\
\text { vitamin D } \\
\text { deficiency }\end{array}$ & $\begin{array}{c}\text { Healthy no } \\
\text { vitamin D } \\
\text { deficiency } \\
\text { (Control) }\end{array}$ \\
\cline { 2 - 5 } & Mean \pm SD & Mean \pm SD & Mean \pm SD & Mean \pm SD \\
\hline FBS before taken vitamin D & $180 \pm 24$ & $171 \pm 21$ & $78 \pm 11$ & $80 \pm 12$ \\
FBS after treatment with & $151 \pm 22$ & $171 \pm 22$ & $85 \pm 12$ & $80 \pm 20$ \\
vitamin D & & & & \\
HbA1c before treatment & $8.8 \pm 1$ & $8.3 \pm 1$ & $4.3 \pm 0.6$ & $4.0 \pm 0.7$ \\
with vitamin D treatment & $7.5 \pm 1$ & $8.3 \pm 1.2$ & $4.3 \pm 0.6$ & $4.5 \pm 0.8$ \\
HbA1c after taken vitamin D & $109 \pm 10$ & $124 \pm 3$ & $65 \pm 7$ & $94 \pm 8$ \\
TG & $113 \pm 12$ & $175 \pm 16$ & $72 \pm 10$ & $93 \pm 11$ \\
S. cholesterol & $65 \pm 6$ & $122 \pm 14$ & $77 \pm 6$ & $70 \pm 8$ \\
LDL & $45 \pm 5$ & $33 \pm 2$ & $52 \pm 6$ & $55 \pm 4$ \\
HDL & $22 \pm 1$ & $24 \pm 3$ & $13 \pm 1$ & $19 \pm 2.4$ \\
VLDL & $76 \pm 4$ & $81 \pm 12$ & $76 \pm 10$ & $81 \pm 11$ \\
weight & $26.5 \pm 4$ & $27.5 \pm 2$ & $26.9 \pm 4$ & $23.9 \pm 3$ \\
BMI & & &
\end{tabular}

In regard FBS in both type 1 and 2 diabetes mellitus have found dropped significant after vitamin D treatment from $187 \mathrm{mg} / \mathrm{dl}$ to $166 \mathrm{mg} / \mathrm{dl}$ in T1DM and $171 \mathrm{mg} / \mathrm{dl}$ to $153 \mathrm{mg} / \mathrm{dl}$ in T2DM $(\mathrm{P}<0.05)$. These values also found dropped in HbA1c in both types of diabetes (table 5).

Table 5. Fasting blood glucose, glycemic control and lipid profile among types of diabetes

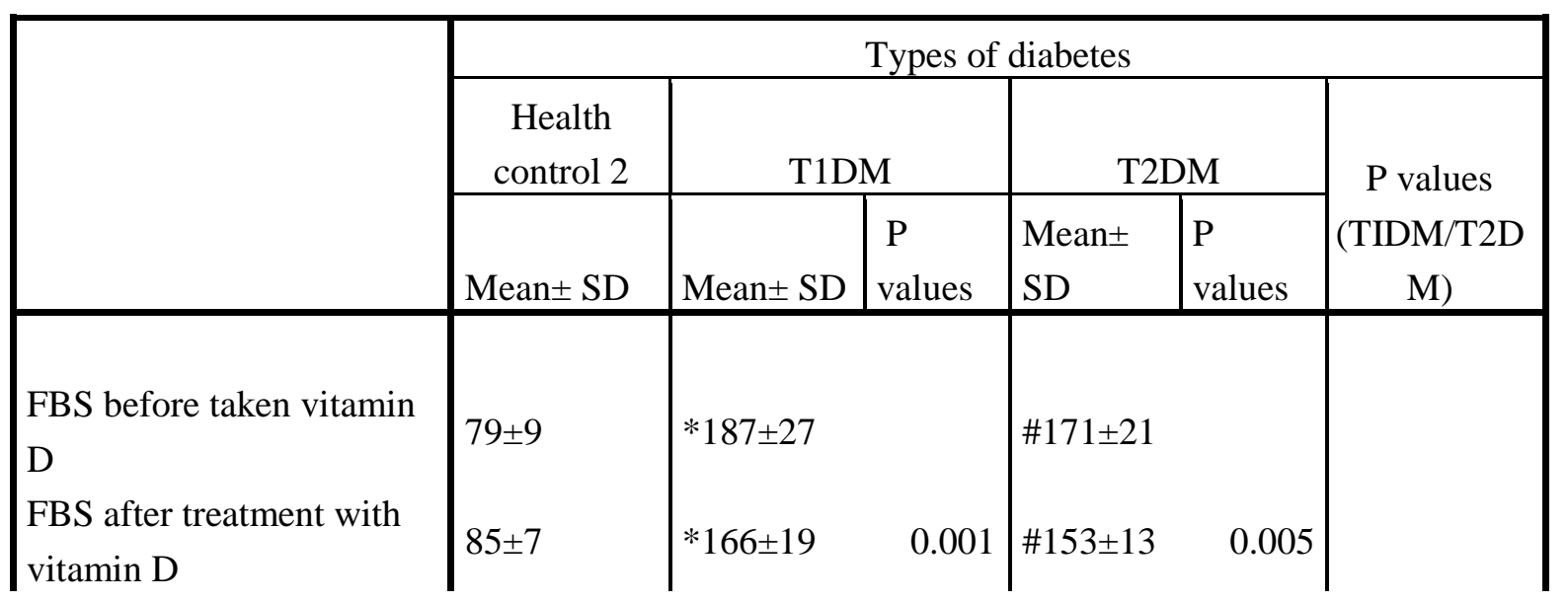


HbA1c before vitamin D treatment

$\mathrm{HbA1c}$ after taken vitamin $\mathrm{D}$ TG

S. cholesterol

LDL

HDL

VLDL

BMI

\begin{tabular}{|l|ll|ll|l|}
$4.6 \pm 0.5$ & $* * 8.8 \pm 0.8$ & & $\# \# 8.5 \pm 0.5$ & & \\
$4.3 \pm 0.2$ & $* * 7.9 \pm 0.4$ & 0.01 & $\# \# 8.0 \pm 0.45$ & 0.04 & \\
$80 \pm 6.8$ & $127 \pm 15$ & & $105 \pm 12$ & & 0.002 \\
$82 \pm 9$ & $133 \pm 12$ & $112 \pm 11$ & \\
$40 \pm 5$ & $90 \pm 6$ & $110 \pm 9$ & \\
$45 \pm 5$ & $43 \pm 4$ & $43 \pm 3$ & \\
$16 \pm 3$ & $25.4 \pm 4$ & $21 \pm 5$ & \\
$28.4 \pm 20$ & $25.9 \pm 4$ & $26.9 \pm 7$ & \\
\hline
\end{tabular}

The comparison has been made between FBS and HbA1C within groups of TIDM and T2DM and between T1DM and T2DM. Student $\mathrm{T}$ test was performed at $\alpha<0.05$ which considered significant. The effect of types of vitamin D treatment on glycemic control, FBS and lipid profile has been investigated and found that both types of vitamin D treatment reduced FBS, $\mathrm{HbAC1}$ but profound and significant effect found on those used vitamin $\mathrm{D}$ tablet $(\mathrm{P}<0.05)$ Both treatments found to have improved lipid profile (Table 6).

Table 6. Relation amid types of vitamin D supplement and fasting blood glucose, glycemic control and lipid profile

\begin{tabular}{|c|c|c|c|c|c|c|}
\hline & \multicolumn{6}{|c|}{ Types of vitamin D supplement among diabetic patients } \\
\hline & \multirow{2}{*}{$\begin{array}{c}\text { no } \\
\text { treatment } \\
\text { Mean } \pm \\
\text { SD }\end{array}$} & \multicolumn{2}{|c|}{ injection } & \multicolumn{2}{|c|}{ orally } & \multirow[t]{2}{*}{$P$ values } \\
\hline & & $\begin{array}{l}\text { Mean } \pm \\
\text { SD }\end{array}$ & $p$ values & $\begin{array}{l}\text { Mean } \pm \\
\text { SD }\end{array}$ & P values & \\
\hline FBS before taken vitamin & $91 \pm 11$ & $150 \pm 13$ & & $167 \pm 23$ & & \\
\hline $\begin{array}{l}\text { FBS after treatment with } \\
\text { vitamin } D\end{array}$ & $91 \pm 14$ & $142 \pm 15$ & 0.000 & $143 \pm 12$ & 0.0001 & \\
\hline $\begin{array}{l}\mathrm{HbA} 1 \mathrm{c} \text { before vitamin } \mathrm{D} \\
\text { treatment }\end{array}$ & $5.4 \pm 2$ & $7.4 \pm 0.8$ & & $7.6 \pm 0.9$ & & \\
\hline $\begin{array}{l}\text { HbA1c after taken } \\
\text { vitamin D }\end{array}$ & $5.3 \pm 9$ & $6.9 \pm 0.4$ & 0.01 & $6.9 \pm 0.7$ & 0.02 & \\
\hline TG & $111 \pm 14$ & $131 \pm 21$ & & $95 \pm 11$ & & 0.000 \\
\hline S. cholesterol & $117 \pm 13$ & $129 \pm 24$ & & $102 \pm 8$ & & 0.000 \\
\hline LDL & $34 \pm 7$ & $57 \pm 8$ & & $35 \pm 6$ & & 0.001 \\
\hline HDL & $44 \pm 6$ & $42 \pm 8$ & & $45 \pm 9$ & & 0.06 \\
\hline VLDL & $22 \pm 5$ & $26 \pm 4$ & & $20 \pm 4$ & & 0.00 \\
\hline BMI & $27.6 \pm 3$ & $27.7 \pm 2$ & & $26.3 \pm 5$ & & 0.04 \\
\hline
\end{tabular}

The comparison has been made between FBS and HbA1C within groups vitamin supplement and between orally and injectable vitamin $\mathrm{D}$. Student $\mathrm{T}$ test was performed at $\alpha<0.05$ which considered significant.

In compared to monthly vitamin D supplement, the weekly dose of vitamin D (50, $000 \mathrm{IU})$ was show has more significant effect on reducing FBS , HbA1C, lipid profile and BMI as shown in Table 7. 
Asian Journal of Basic Science \& Research

Volume 3, Issue 3, Pages 25-35, July-September 2021

Table 7. Relation between vitamin D doses, fasting blood glucose, glycemic control and lipid profile

\begin{tabular}{|c|c|c|c|c|c|c|}
\hline & \multicolumn{5}{|c|}{ Dose of vitamin D } & \multirow[b]{3}{*}{$\begin{array}{c}\mathrm{P} \\
\text { values }\end{array}$} \\
\hline & \multirow{2}{*}{$\begin{array}{c}\text { No dose } \\
\text { Mean } \pm \text { SD }\end{array}$} & \multicolumn{2}{|c|}{ Weekly $(50,000 \mathrm{IU})$} & \multicolumn{2}{|c|}{ Monthly (variable) } & \\
\hline & & Mean \pm SD & $\mathrm{P}$ values & $\begin{array}{l}\text { Mean } \pm \\
\text { SD }\end{array}$ & $\begin{array}{l}\mathrm{P} \\
\text { values }\end{array}$ & \\
\hline $\begin{array}{l}\text { FBS before taken vitamin } \\
\text { D }\end{array}$ & $137 \pm 17$ & $176 \pm 22$ & & $157 \pm 16$ & & \\
\hline $\begin{array}{l}\text { FBS after treatment with } \\
\text { vitamin D }\end{array}$ & $139 \pm 18$ & $149 \pm 17$ & 0.000 & $141 \pm 25$ & 0.04 & \\
\hline $\begin{array}{l}\text { HbA1c before vitamin D } \\
\text { treatment }\end{array}$ & $6.4 \pm 1$ & $8.4 \pm 1$ & & $8.5 \pm 1.5$ & & \\
\hline $\begin{array}{l}\text { HbA1c after taken } \\
\text { vitamin D }\end{array}$ & $6.4 \pm 0.8$ & $7.8 \pm 1$ & 0.02 & $8.2 \pm 0.99$ & & \\
\hline TG & $111 \pm 11$ & $99 \pm 13$ & & $130 \pm 15$ & & 0.000 \\
\hline S. cholesterol & $117 \pm 22$ & $107 \pm 18$ & & $126 \pm 21$ & & 0.000 \\
\hline LDL & $34 \pm 4$ & $60 \pm 7$ & & $100 \pm 17$ & & 0.000 \\
\hline HDL & $47 \pm 5$ & $43 \pm 3$ & & $40 \pm 6$ & & \\
\hline VLDL & $22 \pm 4$ & $20 \pm 3$ & & $26 \pm 5$ & & 0.02 \\
\hline BMI & $27.6 \pm 3$ & 26. & \pm 6 & 27. & & 0.03 \\
\hline
\end{tabular}

The comparison has been made between FBS and HbA1C within groups and between weekly and monthly vitamin $\mathrm{D}$ doses. Student $\mathrm{T}$ test was performed at $\alpha<0.05$ which considered significant.

In the next, further investigate one of confound factors such as physical activities on glycemic and lipid profile, The result in Table 8 shown that no active and low active patients have much better improved FBS, glycemic control, lipid profile but worse BMI than moderate and high physical activities (Table 8).

Table 8. Effect of physical activities on fasting blood glucose, glycemic control and lipid profile

\begin{tabular}{|c|c|c|c|c|}
\hline & \multicolumn{4}{|c|}{ Types of physical activities } \\
\hline & no active & Low & Moderate & high \\
\hline & Mean \pm SD & Mean \pm SD & Mean \pm SD & Mean \pm SD \\
\hline $\begin{array}{l}\text { FBS before taken vitamin } \\
\text { D }\end{array}$ & $150 \pm 14$ & $164 \pm 16$ & $186 \pm 23$ & $76 \pm 12$ \\
\hline $\begin{array}{l}\text { FBS after treatment with } \\
\text { vitamin D }\end{array}$ & $138 \pm 12$ & $141 \pm 15$ & $180 \pm 21$ & $80 \pm 11$ \\
\hline $\begin{array}{l}\text { HbA1c before vitamin D } \\
\text { treatment }\end{array}$ & $6.9 \pm 1$ & $8.0 \pm 1.6$ & $9.1 \pm 1.9$ & $9 \pm 2.1$ \\
\hline
\end{tabular}




\begin{tabular}{|l|c|c|c|c|} 
HbA1c after taken & $6.6 \pm 1.1$ & $7.3 \pm 1.6$ & $8.7 \pm 1.5$ & $8.9 \pm 2$ \\
vitamin D & $105 \pm 21$ & $109 \pm 11$ & $186 \pm 16$ & $129 \pm 24$ \\
S. cholesterol & $108 \pm 12$ & $129 \pm 23$ & $88 \pm 9$ & $150 \pm 17$ \\
LDL & $37 \pm 2$ & $45 \pm 7$ & $19 \pm 3$ & $78 \pm 8$ \\
HDL & $44 \pm 7$ & $39 \pm 6$ & $48 \pm 8$ & $41 \pm 5$ \\
VLDL & $21 \pm 2$ & $22 \pm 7$ & $37 \pm 7$ & $26 \pm 5$ \\
BMI & $27.3 \pm 4$ & $26.4 \pm 8$ & $26.7 \pm 3$ & $22.6 \pm 6$ \\
\hline
\end{tabular}

The comparison has been made between FBS and HbA1C within same groups physical activities and Student T test was performed at $\alpha<0.05$ which considered significant.

\section{Discussions}

The present study revealed that, Vitamin D supplementation in diabetic patients has vitamin D deficiency found to have improved roles in FBS and HbA1C. These found have been demonstrated in several studies carried by $\mathrm{Hu}$, et al., (21), Kostoglou et al (22) and Li et al (23). In the most studies conducts in field of vitamin D and diabetes in which Vitamin D has linked to improved FBS and HbA1C in type 2 diabetes mellitus.

According to our knowledge no study highlighted the role of vitamin D in lowered both FBS and HbA1C. Our study considered first study highlighted role of vitamin D in lowering of glycemic control and FBS in Type1 diabetes mellitus. In the present study there also found that vitamin D supplementation improve lipid profile in diabetes patients. In compared to health control subjects, vitamin D lowered serum triglycerides, cholesterol, LDL. In fact majorities of studies were investigated role of vitamin $\mathrm{D}$ in control lipid profile in type 2 diabetes mellitus $(24,25,26)$. Overall this study demonstrated that vitamin D improved serum levels of TC, TG, and LDL in patients with T2D but changes of serum HDL was not satisfactory. Similarly, has been found in studies of effect of vitamin D on lipid profile in Iran (27), and USA (28). However some researches have been studies such effect on types 1 diabetes mellitus but the studies were found no relation between vitamin D and lipid profile $(29,30)$.

The current study further investigated the form and dose of vitamin D that have effect in an improved of FBS, glycemic control, lipid profile and found that weekly oral dose in concentration of 50, $000 \mathrm{IU}$ have much improver of serum glucose, HbA1C, lipid profile and BMI than injectable one. However, there were different doses have been found to have significant effect on lowering FBS, HbA1C , lipid profile ranging accordingly from 1000 to 50, 000 IU (31-36). Furthermore cofound factor such as physical activities and types of food intake were also investigated and found that physical activities did not mimic vitamin D effect.

The withdrawal of patients from the study was the major limitation of the study. According the result of this study vitamin D is considered crucial for improved FBS, HbA1C, lipid profile, therefore should be one of the routine supplement to all diabetes patients. Overall, vitamin D supplementation in diabetic patients improved BFS, $\mathrm{HbA1C}$, lipid profile and the suitable dose and form made such affect were weekly orally $50.000 \mathrm{IU}$. This study was highlighted such effect in both types of diabetes. 
Asian Journal of Basic Science \& Research Volume 3, Issue 3, Pages 25-35, July-September 2021

\section{Conclusion}

Vitamin D supplementation for diabetic patients with vitamin D deficiency has been found reduced FBS, HbA1c and improved lipid profile. These lowered and improved values found in both types of DM. Oral supplementation of vitamin D given much better reduction values in FBS, HbA1C, lipid profile and BMI than injectable form of vitamin D. Furthermore the weekly dose of vitamin D has significant impact on FBS, HbA1C, lipid profile and BMI than other times.

Although these effect of vitamin D supplementation was independent factors other than physical activities. Therefore, vitamin D can be considered as a therapeutic agent along with the other treatments for both types of Diabetes mellitus. In addition, the deficiency of vitamin D is associated with an increased level of BMI in the studies of both diabetic and non-diabetic subjects.

\section{Declarations}

\section{Source of Funding}

This research did not receive any specific grant from funding agencies in the public, commercial, or not-for-profit sectors.

\section{Competing Interests Statement}

The authors declare no competing financial, professional and personal interests.

\section{Consent for publication}

We declare that we consented for the publication of this research work.

\section{Ethical Approval}

This study was granted approval by the local Ethics Committee of the Benghazi province. Informed written consent was obtained through a consent form that was given to the participants along with the questionnaire.

\section{Availability of data and material}

Authors are willing to share data and material according to the relevant needs.

\section{References}

1- Wang, H.; Chen, W.; Li, D.; Yin, X.; Zhang, X.; Olsen, N.; Zheng, S.G. Vitamin D and Chronic Diseases. Aging Dis. $2017,8,346-353$.

2- Tao, S.; Yuan, Q.; Mao, L.; Chen, F.-L.; Ji, F.; Cui, Z.-H. Vitamin D deficiency causes insulin resistance by provoking oxidative stress in hepatocytes. Oncotarget 2017, 8, 67605-67613.

3- Tabesh, M.; Azadbakht, L.; Faghihimani, E.; Tabesh, M.; Esmaillzadeh, A. Effects of calcium-vitamin D co-supplementation on metabolic profiles in vitamin D in sufficient people with type 2 diabetes: A randomised controlled clinical trial. Diabetologia 2014, 57, 2038-2047. 
Asian Journal of Basic Science \& Research

Volume 3, Issue 3, Pages 25-35, July-September 2021

4- Upreti, V.; Maitri, V.; Dhull, P.; Handa, A.; Prakash, M.S.; Behl, A. Effect of oral vitamin D supplementation on glycemic control in patients with type 2 diabetes mellitus with coexisting hypovitaminosis D: A parallel group placebo controlled randomized controlled pilot study. Diabetes Metab. Syndr. 2018, 12, 509-512.

5- Barzegari, M.; Sarbakhsh, P.; Mobasseri, M.; Noshad, H.; Esfandiari, A.; Khodadadi, B.; Gargari, B.P. The effects of vitamin D supplementation on lipid profiles and oxidative indices among diabetic nephropathy patients with marginal vitamin D status. Diabetes Metab. Syndr. 2019, 13, 542-547.

6- Mirhosseini, N.; Vatanparast, H.;Mazidi,M.; Kimball, S.M. The Effect of Improved Serum25-Hydroxyvitamin D Status on Glycemic Control in Diabetic Patients: AMeta-Analysis. J. Clin. Endocrinol. Metab. 2017, 102, 30973110.

7- El Hajj, C.; Chardigny, J.-M.; Boirie, Y.; Yammine, K.; Helou, M.;Walrand, S. Effect of Vitamin D Treatment on Glucose Homeostasis and Metabolism in Lebanese Older Adults: A Randomized Controlled Trial. J. Nutr. Health Aging 2018, 22, 1128-1132.

8- Abbas, M.A. Physiological functions of Vitamin D in adipose tissue. J. Ster. Bio. Mol. Biol. 2017, 165, 369-381.

9- Li, Y.-X.; Zhou, L. Vitamin D Deficiency, Obesity and Diabetes. Cell. Mol. Biol. Noisy 2015, 61, 35-38.

10- Holick, M.F. Vitamin D deficiency. N. Engl. J. Med. 2007, 357, 266-281.

11- Gil, Á.; Plaza-Diaz, J.; Mesa, M.D. Vitamin D: Classic and Novel Actions. Ann. Nutr. Metab. 2018, 72, 87-95.

12- Heaney, R.P. Serum 25-hydroxyvitamin D is a reliable indicator of vitamin D status. Am. J. Clin. Nutr. 2011, 94, 619-620.

13- Hossein-Nezhad, A.; et al., M.F. Influence of Vitamin D Status and Vitamin D3 Supplementation on Genome Wide Expression of White Blood Cells: A Randomized Double-Blind Clinical Trial. PLoS ONE 2013, 8, e58725.

14- Pittas AG, Sun Q, Manson JE, et al. Plasma 25-hydroxyvitamin D concentration and risk of incident type 2 diabetes in women. Diabetes Care 2010; 33: 2021-3.

15- Claudia G, Lu ZX, Magliano DJ, et al. Serum 25-hydroxyvitamin D, calcium intake, and risk of type 2 diabetes after 5 years. Diabetes Care 2011; 34: 1133-8.

16- Liu E, Mckeown NM, Pittas AG, et al. Predicted 25-hydroxyvitamin D score and change in fasting plasma glucose in the framingham offspring study. Eur J Clin Nutr 2011; 66: 139-41.

17- Witham MD, Dove FJ, Dryburgh M, et al. The effect of different doses ofvitamin D 3 on markers of vascular health in patients with type 2 diabetes: a randomised controlled trial. Diabetologia 2010; 53: 2112-9.

18- Heshmat R, Tabatabaeimalazy O, et al. Effect of vitamin D on insulin resistance and anthropometric parameters in Type 2 diabetes; a randomized double-blind clinical trial. Daru J Pharma Sci 2012; 20: 10-5.

19- Al-Elq, A.H.; Sadat-Ali, M.; Al-Turki, H.A.; Al-Mulhim, F.A.; Al-Ali, A.K. Is there a relationship between body mass index and serum vitamin D levels? Saudi Med. J. 2009, 30, 1542-1546. 
20- Wang, H., Xia, N., Yang, Y. and Peng, D. Influence of vitamin D supplementation on plasma lipid profiles: a meta-analysis of randomized controlled trials. Lipids Health Dis 2012. 11: 42.

21- Hu Z, Jin' an Chen XS, Wang L, Wang A. Efficacy of vitamin D supplementation on glycemic control in type 2 diabetes patients: A meta-analysis of interventional studies. Medicine. 2019 Jun; 98(14).

22- Kostoglou-Athanassiou I, Athanassiou P, Gkountouvas A, Kaldrymides P. Vitamin D and glycemic control in diabetes mellitus type 2. Therapeutic advances in endocrinology and metabolism. 2013 Aug; 4(4): 122-8.

23- Li X, Liu Y, Zheng Y, Wang P, Zhang Y. The effect of vitamin D supplementation on glycemic control in type 2 diabetes patients: a systematic review and meta-analysis. Nutrients. 2018 Mar; 10(3): 375.

24- Ramiro-Lozano JM, Calvo-Romero JM. Effects on lipid profile of supplementation with vitamin D in type 2 diabetic patients with vitamin D deficiency. Therapeutic advances in endocrinology and metabolism. 2015 Dec; 6(6): 245-8.

25- Saedisomeolia A, Taheri E, Djalali M, Moghadam AM, Qorbani M. Association between serum level of vitamin D and lipid profiles in type 2 diabetic patients in Iran. Journal of Diabetes \& Metabolic Disorders. 2014 Dec 1; 13(1): 7.

26- Jafari T, Fallah AA, Barani A. Effects of vitamin D on serum lipid profile in patients with type 2 diabetes: A meta-analysis of randomized controlled trials. Clinical nutrition. 2016 Dec 1; 35(6): 1259-68.

27- Saedisomeolia A, Taheri E, Djalali M, Moghadam AM, Qorbani M. Association between serum level of vitamin D and lipid profiles in type 2 diabetic patients in Iran. Journal of Diabetes \& Metabolic Disorders. 2014 Dec 1; 13(1): 7.

28- Mohamad MI, El-Sherbeny EE, Bekhet MM. The effect of vitamin D supplementation on glycemic control and lipid profile in patients with type 2 diabetes mellitus. Journal of the American college of nutrition. 2016 Jul 3; 35(5): 399-404.

29- Lieberman R, Wadwa RP, Nguyen N, Bishop FK, Reinick C, Snell-Bergeon JK, Maahs DM. The association between vitamin D and vascular stiffness in adolescents with and without type 1 diabetes. PloS one. 2013 Oct 29; 8(10): e77272.

30- Al Shaikh A, Al Zahrani AM. Impact of vitamin D status on cardiometabolic complications among children and adolescents with type 1 diabetes mellitus. Journal of Clinical Research in Pediatric Endocrinology. 2016 Mar; 8(1): 48 .

31- Wang, T., Pencina, M., Booth, S., Jacques, P., Ingelsson, E., Lanier, K. et al. Vitamin D deficiency and risk of cardiovascular disease. Circulation 2008. 117: 503-511.

32- Mattila, C., Knekt, P., Männistö, S., Rissanen, H., Laaksonen, M., Montonen, J. et al. Serum 25-hydroxy vitamin D concentration and subsequent risk of type 2 diabetes. Diabetes Care 2007. 30: 2569-2570. 
Asian Journal of Basic Science \& Research Volume 3, Issue 3, Pages 25-35, July-September 2021

33- Ponda, M., Dowd, K., Finkielstein, D., Holt, P. and Breslow, J. The short-term effects of vitamin D repletion on cholesterol: a randomized, placebo controlled trial. Arterioscler Thromb Vasc Biol 2013. 32: 2510-2515.

34- Robinson, J., Wang, S., Smith, B. and Jacobson, T. Meta-analysis of the relationship between non-high-density lipoprotein cholesterol reduction and coronary heart disease risk. J Am Coll Cardiol 2009. 53: 316-322.

35- Jorde, R. and Figenschau, Y. Supplementation with cholecalciferol does not improve glycaemic control in diabetic subjects with normal serum 25-hydroxyvitamin D levels. Eur J Nutr 2009. 48: 349-354.

36- Jorde, R. and Grimnes, G. Vitamin D and metabolic health with special reference to the effect of vitamin D on serum lipids. Prog Lipid Res 2011. 50: 303-312. 